\title{
Bubbles or Noise? \\ Reconciling the Results of Broad-Dividend Variance-Bounds Tests
}

\author{
Garrett H. TeSelle*
}

September 1998

\begin{abstract}
Recent research indicates that results of variance-bounds tests of stock price volatility may depend on the definition of cash flows deemed relevant to shareholders: Tests using regular (or "narrow") dividends repeatedly have suggested that stock prices fluctuate more than can be explained by a simple present value hypothesis, while some tests using "broad dividends" (i.e., narrow dividends plus proceeds from share liquidations) do not detect such excess price volatility. Researchers disagree as to the cause and meaning of these differences.

This paper derives and analyzes the broad-dividend version of the present value hypothesis to show that under common assumptions, these differences in variancebounds tests have only two possible causes: Either narrow-dividend tests have rejected the present value hypothesis because of bubbles (either rational bubbles, or "empirical" bubbles as might be effected by dividend-smoothing or dividend-nonpayment); or broaddividend tests simply have lacked power to detect mispricing. Using simulation and results from previous studies, this paper demonstrates that the second possible cause the lack of power in broad-dividend tests - most likely explains the differences between narrow- and broad-dividend variance-bounds tests.

*Federal Reserve Board of Governors, Mail Stop 89, Washington DC, 20551. Phone: (202) 452-3046. Fax: (202) 452-5296. E-mail: gteselle@frb.gov. My work has benefited from discussions with Ravi Jagannathan, Stephen LeRoy, Alexander David, John Geweke, Paul Harrison, Michael Keane, Yuichi Kitamura, Steven Sharpe, Brian Smith, and Kenneth West. I also thank Lucy Ackert and Brian Smith for sharing their data. I am responsible for any errors or omissions. The views presented are solely those of the author and do not necessarily represent those of the Federal Reserve Board or its staff.
\end{abstract}




\section{Introduction}

The fundamental value of any asset typically is equated to the expected discounted value of the payoffs that will be derived from the asset. This noncontroversial tenet is the source of the "present value hypothesis" (PVH), which maintains that the value of a share of stock equals the expected discounted value of its infinite stream of per-share dividends. The PVH has been widely taught, and underlies the "dividenddiscounting" approach to stock valuation that is widely used by many practitioners and academics.

However, the observed volatility of stock prices has been a notable problem for the PVH. Beginning with seminal papers by LeRoy and Porter (1981) and Shiller (1981), stock prices have generally been shown to be more volatile than can be explained by the PVH when calibrated with "reasonable" assumptions for the expectations of discount rates and dividend payments.

The assumptions considered "reasonable" have changed over time. For example, work by Hansen and Jagannathan (1991) and others has convincingly refuted the constant-discount-rate assumption used in early variance-bounds tests. Similarly, a wide variety of assumptions has been made for the statistical properties of the time series of dividends in an effort to deal tractably with their apparent nonstationarity. Despite the many approaches, stock price volatility remains unreconciled with the present value hypothesis. $^{1}$

Some research suggests that the PVH's empirical problems might owe to the inadequacy of dividends as a proxy for the total payoffs to shareholders. For example, Shoven (1987) showed that during periods of high buyout activity, shareholders can receive more payoffs in the form of share liquidations than from dividend payments. Relatedly, it is known that many corporations simply do not pay dividends; for example, Compustat data for 1996 indicate that the set of firms paying no dividends included 68 of the companies in the S\&P 500 index and comprised over 8 percent of the index's total market value. Finally, Marsh and Merton (1986) and others have discussed problems that

1. This paper will not attempt to survey the vast variance-bounds literature. The Appendix provides some basic information on variance-bounds methods (including the West Test) that are particularly pertinent to this paper. It also lists some variance-bounds surveys that readers may find particularly insightful. 
can arise in variance-bounds tests if corporate managers smooth dividends over time. These results suggest it may be fallacious to believe that investors' expectations of total future payoffs can be reliably estimated by statistical extrapolation of historical dividends.

One effort to overcome this concern involves the use of "broad dividends", which are defined as the total payoffs made to shareholders, including dividends and payouts from all stock liquidations. Ackert and Smith (1993) find that a variance-bound volatility test detects excess price volatility when payoffs are represented by "narrow dividends" (i.e., the ordinary per-share dividends used in preceding variance-bounds tests), but not when payoffs are represented by broad dividends. They conclude that the PVH holds when broad dividends (not narrow dividends) are used as the measure of payoffs to shareholders.

These results have influenced recent research. Penman and Sougiannis (1997) use the broad-dividend approach when comparing dividend-discounting against other methods of forecasting prices over finite horizons. Pontiff (1997) notes the Ackert and Smith result indicates that "inferences from variance-bounds tests ... are sensitive to the inclusion of different types of shareholder distributions", and hence seeks evidence of excess volatility that is unaffected by concerns over dividend definitions.

However, the broad-dividend approach also has raised questions. Campbell, Lo, and McKinlay (1997, p.256) point out that stock repurchases and similar share liquidations (which constitute the key difference between narrow and broad dividends) are irrelevant to the present value formula; thus it is not clear why the two approaches might yield different results in variance-bounds tests. Relatedly, LeRoy and TeSelle (1995) discuss an apparent inconsistency when narrow- and broad-dividend approaches yield identical shareholder returns but different volatility test results.

\section{This Paper}

This paper reconciles the conflicting views of the broad-dividend approach. The paper's first contribution is a derivation of the present value hypothesis from the well known "Euler equation", in a manner that nests both the broad- and narrow-dividend approaches. This nesting then is utilized to directly compare the theoretical and empirical attributes of the two approaches. 
In this comparison, particular attention is paid to the case in which broad and narrow dividends differ only because of share liquidations that are always transacted at the concurrent market price. This case is important for two reasons: First, methods used to construct broad dividend data typically cause the broad and narrow dividend series to be linked in this fashion; ${ }^{2}$ second, these traits have important implications for the theoretical and empirical attributes of the broad-dividend approach (vis-a-vis those of the narrow-dividend approach).

The results show that the two approaches are often equivalent theoretically, in the sense that the present value hypothesis is satisfied under the broad approach if and only if it is satisfied under the narrow approach, up to differences related to the possible existence of rational bubbles. Their near-equivalence derives from the equivalence of returns (and hence the equivalence of the Euler conditions) under the two approaches.

However, the results show that even when the two constructs are theoretically equivalent, they are not empirically equivalent. Volatility studies performed using the narrow approach may reject the PVH, while the same test performed using the broad approach may fail to reject; such empirical differences can arise without sampling error. Further, neither approach is universally superior as a basis for empirical tests: In some circumstances (such as dividend-smoothing or absence of dividends) the broad approach can help reduce false rejections of the PVH that might result from perceived bubbles; however, more generally, the broad-dividend approach can have significantly less power than the narrow approach to detect excess share-price volatility. ${ }^{3}$ The paper uses simulation to show that this potential loss of power likely accounted for Ackert and Smith's differing volatility test results for the narrow and broad constructs.

The paper is organized as follows. Section I derives the present value hypothesis

2. Broad dividend series are generally constructed for groups of stocks (such as all firms in an index) following Shoven (1987): Liquidation proceeds are estimated by identifying decreases (but not increases) in total shares outstanding for each firm in the index, valued at the corresponding firm's per-share market price at the time of liquidation.

3. It is well known (e.g., see Cochrane (1991) or Schwert (1991)) that volatility tests cannot distinguish between true pricing errors (e.g. by irrational investors) and model misspecification (by the researcher). I will use terms such as "excess" volatility or "mispricing" generically to refer to any behavior of observed prices inconsistent with the researcher's model for dividends and discount rates. 
in a manner that nests both the broad and narrow dividend approaches, and discusses the near equivalence of the present value hypothesis and the Euler condition. Using these results, Section II demonstrates conditions under which the present value hypotheses of the two approaches will be theoretically equivalent. Section III then shows how the two approaches can yield differing results in variance-bounds volatility tests, even when the underlying present value hypotheses are theoretically equivalent. One potential cause of such differences is the diminished power of the broad-dividend approach to detect mispricing, which is demonstrated by simulation in Section IV. The final section concludes.

\section{The Euler Equation and the Present Value Hypothesis}

As is well known, the present value hypothesis can be derived from the Euler equation, which relates a stochastic discount factor and asset returns:

$$
E_{t}\left(\gamma_{t+1} \Re_{t+1}\right)=1
$$

where

$$
\begin{aligned}
& E_{t} \equiv \text { the expectation operator, conditioned on information available at time } t \\
& \gamma_{t+1} \equiv \text { the stochastic discount factor obtaining in period } t+1 \\
& \Re_{t+1} \equiv \text { the gross return obtaining in period } t+1
\end{aligned}
$$

This equality arises as a necessary condition for constrained utility maximization and as a necessary condition for the absence of arbitrage opportunities in prices of tradable assets. In this paper, we will say that the Euler condition is satisfied by positive sequences $\left\{\gamma_{t}\right\}$ and $\left\{\mathfrak{R}_{t}\right\}$ if equation 1 is satisfied for all $t$.

The literature's standard derivation of the present value hypothesis assumes that the payoff from holding a share of stock will be composed of its next-period price plus the next-period dividend, so that the return is given by 


$$
\Re_{t+j}=r_{t+j} \equiv \frac{p_{t+j}+d_{t+j}}{p_{t+j-1}}
$$

Substitution into the Euler equation (with the assumption that the price $p_{t}$ is in the agent's information set at time $t$, denoted by $I_{t}$ ) then gives

$$
p_{t}=E_{t}\left(\gamma_{t+1} p_{t+1}\right)+E_{t}\left(\gamma_{t+1} d_{t+1}\right)
$$

The standard derivation then assumes that the asset will be held in the agent's portfolio forever, so that the above relationship for price can be iterated indefinitely into the future, resulting in the present value hypothesis

$$
\begin{gathered}
p_{t}=\sum_{j=1}^{\infty} E_{t}\left(\beta_{t, t+j} d_{t+j}\right)+b_{t} \\
\beta_{t, t+j} \equiv \prod_{k=1}^{j} \gamma_{t+k}>0
\end{gathered}
$$

The term $b_{t}$ is the familiar "rational bubble" component, which satisfies the relationships

$$
\begin{aligned}
b_{t} & \equiv \lim _{j \rightarrow \infty} E_{t}\left(\beta_{t, t+j} p_{t+j}\right) \\
& =E_{t}\left(\gamma_{t+1} b_{t+1}\right)
\end{aligned}
$$

We will refer to equations 3 as the Narrow Present Value Hypothesis (NPVH), and the variables $p_{t}, d_{t}, b_{t}, r_{t}$ respectively as the narrow price, narrow dividend, narrow bubble, and narrow return. The case in which there is no bubble (i.e.., the narrow bubble is identically zero) will be denoted by NPVH-NB: 


$$
p_{t}=\sum_{j=1}^{\infty} E_{t}\left(\beta_{t, t+j} d_{t+j}\right)
$$

In this paper, we will assume that all share prices and dividends are nonnegative with certainty, which implies that any rational bubble will also be nonnegative. Also, as pointed out by Diba and Grossman (1988), if a rational bubble is zero-valued in any period, it will almost surely be zero-valued in all future periods.

\section{The Broad Present Value Hypothesis}

Proponents of the "broad-dividend" approach are not comfortable with the narrow construct's assumption that the asset is certain to be held indefinitely into the future. They argue that the present value hypothesis and any tests (such as variance-bounds volatility tests) derived from it should be revised to consider that liquidations may invalidate the "buy-and-hold" assumption in a model of stock pricing. However, no formal derivation of the broad-dividend version of the present value hypothesis has been provided in the literature to date.

To generalize the present value hypothesis to include the possible future liquidation of the asset, note that one-period payoffs will be derived from the next-period price and dividend only if the share is not liquidated; if liquidation occurs, the return will be generated only by the liquidation proceeds. Algebraically, the one-period "broad return" is therefore given by

$$
\Re_{t+1}=R_{t+1} \equiv s_{t+1} r_{t+1}+\left(1-s_{t+1}\right)\left(\frac{L_{t+1}}{p_{t}}\right)
$$

where 
$s_{t+j} \equiv \mathrm{l}$ if the security survives in (i.e., has not been liquidated by) period $t+\mathrm{j}$

$s_{t+j} \equiv 0$ if the security has been liquidated by period $t+j$

$p_{t+j} \equiv$ share price in period $t+j$ if $s_{t+j}=1 ; \equiv 0$ otherwise

$r_{t+j} \equiv$ narrow (per-share) return in period $t+j$ if $s_{t+j}=1 ; \equiv 0$ otherwise

$L_{t+j} \equiv$ share liquidation proceeds in period $t+j$ if $\left(s_{t+j-1}-s_{t+j}\right)=1 ; \equiv 0$ otherwise

and, as a technical matter, we will define $R_{t+j} \equiv 0$ whenever $s_{t+j-1}=0$.

Because the share is held in period $t$, we have $s_{t}=1$. Then, using the definition of the narrow return from equation 2 , the one-period broad return can be written as

$$
R_{t+1}=\frac{s_{t+1}\left(p_{t+1}+d_{t+1}\right)+\left(s_{t}-s_{t+1}\right)\left(L_{t+1}\right)}{s_{t} p_{t}}
$$

Defining the "broad price" and "broad dividend" as, respectively,

$$
\begin{aligned}
& P_{t+j} \equiv s_{t+j} p_{t+j} \\
& D_{t+j} \equiv s_{t+j} d_{t+j}+\left(s_{t+j-1}-s_{t+j}\right) L_{t+j}
\end{aligned}
$$

the broad return takes the same general form as the narrow return:

$$
R_{t+1}=\frac{P_{t+1}+D_{t+1}}{P_{t}}
$$

Using these broad variables, we can apply to the Euler condition the same iterative process that we used for the narrow definitions, without the need for a buy-andhold assumption. This results in the broad present value hypothesis (BPVH) 


$$
\begin{gathered}
P_{t}=\sum_{j=1}^{\infty} E_{t}\left(\beta_{t, t+j} D_{t+j}\right)+B_{t} \\
\beta_{t, t+j} \equiv \prod_{k=1}^{j} \gamma_{t+k}>0
\end{gathered}
$$

with the bubble component (possibly identically zero) satisfying the same key properties already described for the narrow bubble:

$$
\begin{aligned}
B_{t} & \equiv \lim _{k \rightarrow \infty} E_{t}\left(\beta_{t . t+k} P_{t+k}\right) \\
& =\lim _{k \rightarrow \infty} E_{t}\left(\beta_{t . t+k} s_{t+k} p_{t+k}\right) \\
& =E_{t}\left(\gamma_{t+1} B_{t+1}\right)
\end{aligned}
$$

When the sequence of shares is restricted to be nonnegative, the broad bubble will also be nonnegative with certainty, and zero-valuation of the broad bubble in any period implies that the bubble will almost surely be zero-valued in all future periods.

The case in which BPVH is satisfied with no bubble is denoted as BPVH-NB:

$$
P_{t}=\sum_{j=1}^{\infty} E_{t}\left(\beta_{t, t+j} D_{t+j}\right)
$$

Note that the above single-share derivation of BPVH and BPVH-NB can also be applied to portfolios of identical shares by simply redefining $s_{t+j}$ to be the percentage of period- $t$ shares that have not been liquidated by period $t+j$; linearity then shows that the same BPVH equation would also hold if we defined $s_{t+j}$ as the actual number of shares held at the end of period $t+j$. Note that with any of these definitions, the focus on liquidations (and the exclusion of any new purchases of shares) implies that the sequence 
$\left\{s_{t}\right\}$ will be monotonically nonincreasing; this trait will be important when we compare various properties of the narrow- and broad-dividend tests. ${ }^{4}$ Note also that BPVH and BPVH-NB are generalizations of NPVH and NPVH-NB, in which $s_{t+j} \equiv 1$ for all $j>0$ (i.e., period- $t$ shares are never liquidated).

\section{Equivalence of the PVH and Euler Condition}

The above derivations demonstrate that the narrow and broad present value hypotheses are each necessary conditions of their respective Euler conditions (plus the harmless assumption that the current price variable is in the agent's current information set). Conversely, by assuming that the historical discount rates and dividend variables are in the agent's information set, it is easy to see that the respective Euler conditions are often implied by the narrow and broad present value hypotheses. For example, if BPVH is satisfied, with

$$
\begin{aligned}
& \forall t, j \geq 0 \\
& P_{t}=\sum_{k=1}^{\infty} E_{t}\left(\beta_{t, t+k} D_{t+k}\right)+B_{t} \\
& B_{t}=E_{t}\left(\beta_{t, t+1} B_{t+1}\right) \\
& \beta_{t, t+j}>0 ; \beta_{t+j, t+j}=1 \\
& P_{t+j}, D_{t+j} \in I_{t+j}
\end{aligned}
$$

and if discount rates are time-consistent in the sense that for $k \geq 1^{5}$

4. This paper's focus on liquidations of shares (and exclusion of share purchases) is consistent with the current literature on the broad-dividend approach. However, the general equations shown above can be adapted when purchases are allowed; the term $\left(s_{t+j-1}-s_{t+j}\right) L_{t+j}$ is then replaced by the net cash proceeds (i.e., total liquidation proceeds less total purchase costs). Such an analysis might be useful if owners of existing shares hold warrants or other privileges that might allow them to obtain shares at below-market prices.

5. Note that these time-consistency conditions are satisfied if discount rates are constant. 


$$
\begin{aligned}
\beta_{t+j-k, t+j} & \in I_{t+j} \\
E_{t}\left(\beta_{t, t+k} D_{t+k}\right) & =E_{t}\left(\beta_{t, t+1} \beta_{t+1, t+k} D_{t+k}\right)
\end{aligned}
$$

Then denoting $\gamma_{t+1} \equiv \beta_{t, t+1}$,

$$
\begin{aligned}
P_{t} & =\sum_{j=1}^{\infty} E_{t}\left(\beta_{t, t+j} D_{t+j}\right)+B_{t} \\
& =E_{t}\left(\gamma_{t+1} D_{t+1}\right)+E_{t}\left\{\gamma_{t+1}\left[\sum_{j=1}^{\infty} E_{t+1}\left(\beta_{t+1, t+1+j} D_{t+1+j}\right)+B_{t+1}\right]\right\} \\
& =E_{t}\left(\gamma_{t+1} D_{t+1}\right)+E_{t}\left(\gamma_{t+1} P_{t+1}\right) \\
& =E_{t}\left[\gamma_{t+1}\left(P_{t+1}+D_{t+1}\right)\right]
\end{aligned}
$$

The broad Euler equation is obtained by dividing each side by the known (at time $t$ ) broad price $P_{t}$. The narrow Euler condition is similarly obtained from the NPVH and corresponding assumptions on the agent's information set. Thus, with minimal assumptions on the information sets, the narrow and broad present value hypotheses are equivalent to the Euler conditions formed with their respective returns variables:

$N P V H \Leftrightarrow$ Narrow Euler condition (i.e., with $\Re \equiv \mathrm{r}$ ) $B P V H \leftrightarrow$ Broad Euler condition (i.e., with $\Re \equiv \mathrm{R}$ )

\section{Theoretical Near-Equivalence of the Broad and Narrow Constructs}

Because it is more general, one might suspect that the broad construct is more 
advantageous as a model of asset pricing. However, when applied to a stock index or other non-vanishing portfolio (i.e., a portfolio for which $s_{t} p_{t}>0$ for all $t$ ), the broad and narrow constructs will be nearly equivalent in the absence of arbitrage opportunities in liquidation prices.

To see this, note that for any nonvanishing portfolio, equations 2 and 6 imply

$$
R_{t+1} \equiv r_{t+1}+\frac{\left(s_{t}-s_{t+1}\right)\left[L_{t+1}-\left(p_{t+1}+d_{t+1}\right)\right]}{s_{t} p_{t}}
$$

Thus, if $\gamma_{\mathrm{t}+1}$ is any finite-variance random variable ${ }^{6}$

$$
E_{t}\left(\gamma_{t+1} r_{t+1}\right)=E_{t}\left(\gamma_{t+1} R_{t+1}\right)
$$

if and only if

$$
E_{t}\left[\gamma_{t+1} A_{t+1}\right]=0
$$

where

$$
A_{t+1} \equiv\left(s_{t}-s_{t+1}\right)\left[L_{t+1}-\left(p_{t+1}+d_{t+1}\right)\right]
$$

denotes the arbitrage effect that the investor realizes by transferring shares at the liquidation value $\left(L_{t+1}\right)$ rather than at the cum-dividend price at the time of liquidation. If equation 12 is satisfied, the narrow and broad Euler conditions are clearly equivalent:

$$
\left\{E_{t}\left(\gamma_{t+1} r_{t+1}\right)=1\right\} \Leftrightarrow\left\{E_{t}\left(\gamma_{t+1} R_{t+1}\right)=1\right\}
$$

6. I assume that both sides of equation 11 are finite, as will be the case whenever the time- $t$ conditional variances of the one-period returns and discount factor are finite. 
No-Arbitrage Liquidation Pricing

As discussed earlier, satisfaction of the Euler equation is a necessary condition for the absence of arbitrage opportunities in the prices of investments available to the representative agent. Likewise, if any agent with strictly increasing utility is able to freely buy and sell shares at the time of liquidation, the existence of equilibrium prices (i.e., the absence of arbitrage possibilities) implies that

$$
L_{t+j} \equiv p_{t+j}+d_{t+j}
$$

As a result, equations 10 through 14 indicate that returns and Euler conditions will be equivalent under the broad and narrow approaches in all periods, for any process on discount rates and for any nonvanishing pattern of share liquidations or purchases. Further, the equivalence of the Euler conditions and present value hypotheses implies that the NPVH and BPVH will also be equivalent:

$$
r_{t+j} \equiv R_{t+j}
$$

NPVH $\Leftrightarrow$ Narrow Euler condition $\Leftrightarrow$ Broad Euler condition $\Leftrightarrow B P V H$

Thus, any hope that the NPVH and BPVH are not equivalent depends in part on showing that some institutional factors prevent a representative agent from exploiting arbitrage opportunities arising from price relationships that do not satisfy equation 15.

\section{Bubbles in Broad and Narrow Prices}

However, the above equivalence of NPVH and BPVH does not extend to their nobubble counterparts NPVH-NB and BPVH-NB. Specifically, satisfaction of NPVH-NB is sufficient (but not necessary) for the satisfaction of BPVH-NB when the share sequence includes liquidations but not purchases (i.e., when $\left\{s_{t+j}\right\}$ is monotonically nonincreasing).

It is easily seen that NPVH-NB implies BPVH-NB. When NPVH-NB is satisfied, 
then certainly so is NPVH (with $b_{t} \equiv 0$ ); satisfaction of BPVH is then implied by the equivalence of NPVH and BPVH. Finally, BPVH-NB is implied from the fact that, by the monotonicity of the share sequence, the broad bubble component must be zero-valued:

$$
\begin{aligned}
B_{t} & =\lim _{k \rightarrow \infty} E_{t}\left(\beta_{t, t+k} P_{t+k}\right) \\
& \equiv \lim _{k \rightarrow \infty} E_{t}\left(\beta_{t, t+k} s_{t+k} p_{t+k}\right) \\
& \leq s_{t} \lim _{k \rightarrow \infty} E_{t}\left(\beta_{t, t+k} p_{t+k}\right) \\
& =s_{t} b_{t} \\
& =0
\end{aligned}
$$

However, the converse is not true. As suggested by the following observation, the existence of a bubble in the broad construct requires not only the existence of a narrow bubble (as shown above), but also sufficiently slow liquidation of the share sequence.

Observation: Even with a rational bubble in the narrow price, there will be no bubble in the broad price if the number of shares $\left(s_{t+k}\right)$ is sure to decline faster than the rate of growth of the discounted price $\left(\beta_{t, t+k} p_{t+k}\right)$.

This is readily seen when discount rates and price growth rates are bounded. Suppose there exist positive numbers $\beta, g_{p}$ such that for all $t, k$

$$
\begin{aligned}
\beta_{t, t+k} & <\beta^{k} \\
p_{t+k} & <p_{t} g_{p}^{k}
\end{aligned}
$$

almost surely. Further suppose there also exists $\mathscr{g}_{s}>\beta \mathfrak{g}_{p}$ such that for all $t, k$ the share 
sequence $\left\{s_{t}\right\}$ will almost surely satisfy

$$
s_{t+k}<s_{t} g_{s}^{-k}
$$

Then there can be no broad bubble, even if a narrow bubble exists, because for all $t$

$$
B_{t} \equiv \lim _{k \rightarrow \infty} E_{t}\left[\beta_{t, t+k} s_{t+k} p_{t+k}\right] \leq s_{t} p_{t} \lim _{k \rightarrow \infty}\left(\frac{\beta_{\mathscr{g}_{p}}}{\overline{g_{s}}}\right)^{k}=0
$$

These relationships among the various hypotheses under the assumption of noarbitrage liquidation pricing and monotonically nonincreasing shares are thus summarized as

$$
\begin{aligned}
& N P V H-N B \Rightarrow B P V H-N B \\
& \Downarrow \\
& \text { Narrow Euler condition } \Leftrightarrow N P V H \leftrightarrow B P V H \leftrightarrow \text { Broad Euler condition }
\end{aligned}
$$

Note that NPVH and BPVH are equivalent, but the logical relationship between their no-bubble counterparts is one-way as a result of the above observation.

\section{Empirical Non-Equivalence of the Narrow and Broad Constructs}

The theoretical near-equivalence of the broad and narrow versions of the PVH does not imply their equivalence for empirical tests. That is, a volatility test of narrow prices and dividends may reject the $\mathrm{PVH}$, even though the same test would fail to reject the PVH when performed using broad prices and dividends. Additionally, the two sets of variables can have different stationarity properties that would require modifications to test procedures. The following examples may be useful. 
Example 1 (General Model) - A firm begins period 1 with $s_{0}=1$ perfectly divisible share outstanding, no debt, and $V_{0}=1$ unit of perfectly divisible and nondepreciating assets. In each period $t \geq 1$, the firm earns $y_{t}$ on each unit of assets held at the beginning of the period, so its total earnings for the period is $y_{t} V_{t-1}$. The returns technology is available to everyone, and there are no taxes or other frictions; hence the total market value of the firm will always equal its asset holdings. At the end of each period $t \geq 1$, the firm pays total dividends to shareholders in the amount of $x_{t} V_{t-1}$, which is divided equally among the $s_{t-1}$ shares outstanding at the time of dividend payment. For simplicity, assume that $y_{t}$ and $x_{t}$ follow independent iid processes with bounded and positive support, and that the support of $y_{t}$ exceeds that of $x_{t}$, so that the rate $z_{t} \equiv y_{t}-x_{t}$ of after-dividend earnings is always positive. A portion $(0 \leq \lambda \leq 1)$ of the after-dividend earnings are then "reinvested" as additions to the firm's assets for the next period (thereby increasing assets by $\left.\lambda z_{t} V_{t-1}\right)$, and the remaining earnings $\left(=(1-\lambda) z_{t} V_{t-1}\right)$ are used by the firm to repurchase shares at the concurrent (ex-dividend) market price. The discount rate is assumed to be $\beta=\left(1+\mu_{\mathrm{y}}\right)^{-1}$, where $\mu_{\mathrm{y}} \equiv \mathrm{E}\left(y_{t}\right)$.

It is straightforward to show that the total market capitalization (= total assets $\left.V_{t}\right)$, the number of shares outstanding $\left(s_{t}\right)$, narrow (per-share) price $\left(p_{t}\right)$, and narrow (pershare) dividend $\left(d_{t}\right)$ at the end of each period $t$ will be

$$
\begin{aligned}
& V_{t}=\prod_{i=1}^{t}\left(1+\lambda z_{i}\right) \\
& s_{t}=\prod_{i=1}^{t}\left(\frac{1+\lambda z_{i}}{1+z_{i}}\right) \\
& p_{t}=\prod_{i=1}^{t}\left(1+z_{i}\right) \\
& d_{t}=x_{t} \prod_{i=1}^{t-1}\left(1+z_{i}\right)
\end{aligned}
$$

Notice that the per-share price and dividend values do not depend on $\lambda$, and are therefore the same for any level of repurchase activity. Stationarity of the narrow price 
and dividend can be achieved by dividing by current dividend values, with

$$
\begin{gathered}
\frac{p_{t}}{\overline{d_{t}}}=\frac{\underline{1+z_{t}}}{x_{t}} \\
E_{t}\left(\frac{d_{t+j}}{\underline{d_{t}}}\right)=\mu_{x}\left(1+\mu_{z}\right)^{j-1}\left(\frac{p_{t}}{\underline{d_{t}}}\right)
\end{gathered}
$$

and NPVH-NB can be shown to hold.

For a portfolio encompassing all outstanding shares, the broad price and dividend values will be

$$
\begin{aligned}
& P_{t}=V_{t}=\prod_{i=1}^{t}\left(1+\lambda z_{i}\right) \\
& D_{t}=\left(y_{t}-\lambda z_{t}\right) \prod_{i=1}^{t-1}\left(1+\lambda z_{i}\right)
\end{aligned}
$$

As with the narrow variables, stationarity can be induced by dividing broad variables by the current broad dividend, and BPVH-NB can be shown to hold. Unlike the narrow variables, however, broad variables do depend on $\lambda$; in fact, when $\lambda=0$ (i.e., all afterdividend profits are used to repurchase shares), the broad price $\left(P_{t} \equiv 1\right)$ and dividend $\left(D_{t}=y_{t}\right)$ are level-stationary even though the corresponding narrow variables are not.

Example 2 (Dividend Smoothing or No Dividends) - Assume the same general framework as in Example 1, with an iid process on $\left\{y_{t}\right\}$ with support that is strictly positive and bounded from 0 , except now suppose that the firm chooses $x_{t}$ to maintain a constant narrow dividend-per-share $(d)$ until some future period $T$, by setting

$$
x_{t}=d \cdot \prod_{i=1}^{t-1}\left(1+z_{i}\right)^{-1}
$$


for all $t<T$. Note that this level of dividends will be feasible for the firm for any $d$ that is less than the smallest value in the support of $\left\{y_{t}\right\}$. The case $d=0$ depicts a firm paying no dividends. For simplicity, assume $\lambda=0$ (i.e., all after-dividend profits are used to repurchase shares). The above formulas imply that for all $t<T$

$$
\begin{aligned}
& s_{t}=\prod_{i=1}^{t}\left(1+z_{i}\right)^{-1} \\
& p_{t}=\prod_{i=1}^{t}\left(1+z_{i}\right) \\
& d_{t}=d \\
& P_{t}=1 \\
& D_{t}=y_{t}
\end{aligned}
$$

In this case, it is clear that BPVH-NB will hold. A researcher performing a broaddividend volatility test before period $T$ would conclude (correctly) that the constant broad price was not excessively volatile.

Likewise, NPVH-NB also holds; prices fluctuate only as warranted by changes in retained earnings, which investors anticipate receiving at a future time. In particular, prices do not contain any bubble component.

However, a researcher who assumes that future dividends will follow the same path as past narrow dividends would conclude otherwise. Extrapolation of the constant stream of past dividends would cause the researcher to conclude that the expected present value of the future dividend stream is constant, at

$$
p^{*} \equiv E_{t}\left[\sum_{j=1}^{\infty} \beta^{j} d_{t+j}\right]=d \sum_{j=1}^{\infty}\left(\frac{1}{1+\mu_{y}}\right)^{j}=\frac{d}{\mu_{y}}
$$

The mispricing perceived by the researcher would be given by the sequence $\left\{b_{t}{ }^{*}\right\}$, 
with

$$
\begin{aligned}
b_{t}^{*} & =p_{t}-p_{t}^{*} \\
& =\prod_{i=1}^{t}\left(1+z_{i}\right)-\frac{d}{\mu_{y}}
\end{aligned}
$$

Calculation will verify these perceived pricing errors will be nonnegative and will have an expected growth rate of $\beta^{-1}=1+\mu_{y^{\prime}}$ thereby giving them the same traits as a rational bubble. Thus, even though the asset price contains no true rational bubble, the researcher would detect an illusory "empirical bubble" because of the incomplete information set he uses to project future dividends.

Because the narrow dividend stream is constant, the researcher would perceive all price fluctuations as being generated by the perceived bubble; hence he would conclude (incorrectly) that prices were excessively volatile and that NPVH-NB is violated.

These examples demonstrate that differences between the narrow and broaddividend approaches can be important to empirical tests. In general, narrow-construct variables can differ from their broad-construct counterparts in three important ways:

1) Their information content;

2) their statistical properties; and

3) their economic meaning.

\section{1) Information Content}

Flood and Hodrick (1990) note that rational bubbles are observationally equivalent to changes in investors' expectations concerning out-of-sample dividends. If investors foresee the possibility of a post-sample regime shift in the (narrow) dividend process, then revisions in the assessed probability of the regime shift (or changed assessments of the probability distribution of post-shift dividends) could cause share-price fluctuations. These fluctuations are not truly rational bubbles, because they owe to changing expectations of future dividends; however, they may appear as rational bubbles to the 
researcher using the narrow-dividend approach, leading to an expected (possibly erroneous) rejection in any test of NPVH-NB. Such an effect occurred in Example 2.

This difference relates directly to weaknesses of narrow-construct variance-bounds tests that have been discussed in the literature. For example, as has been pointed out by proponents of the broad-dividend approach, the existence of firms that pay no dividends (but have fluctuating, positive prices) might cause rejection in a narrow-dividend variance-bounds test of NPVH-NB, even if price fluctuations reflect rational changes in assessed probabilities that the firms will ultimately reward the patience of shareholders with higher dividends at some future time. More broadly, these no-dividend firms can be considered as extreme examples of "dividend smoothing" by corporate managers. As noted by Gilles and LeRoy (1991), dividend smoothing can cause small-sample problems that impair the links between observed dividend fluctuations and changes in firms' economic value, thereby causing problems in narrow-dividend variance-bounds tests.

By contrast, the broad-dividend approach may be less susceptible to such false rejections, because the construction of the broad-dividend series incorporates information (i.e., the narrow price) that is correlated with the assessments of unobservable future dividends. Just as discussed earlier in the context of rational bubbles, an empirical bubble in the narrow-construct will not be transmitted to the broad construct if the sequence of shares is expected (by the researcher's estimate of the applicable probability distributions) to shrink sufficiently rapidly. Thus, as in Example 2 above, when a narrow-dividend test incorrectly rejects NPVH-NB, the corresponding broad-dividend test may correctly fail to reject BPVH-NB. In this sense, the broad-dividend approach can reduce the likelihood of an incorrect rejection of the no-bubbles present value hypothesis.

Unfortunately, this advantage of the broad approach in the presence of empirical bubbles becomes a disadvantage if a true rational bubble exists in narrow prices. In such cases, the bubble will not be detected in a broad-dividend test of BPVH-NB whenever shares are liquidated sufficiently quickly. ${ }^{7}$

7. This possible failure of the broad-dividend approach to detect rational bubbles is linked to Flood and Hodrick's (1990) observation that (narrow-dividend) volatility tests that include terminal prices as a proxy for unobservable future dividends can fail to detect rational bubbles. The use of such a terminal price equates to a broad-dividend test in which the sequence of shares is constant until the final sample period, when it immediately and permanently shrinks to zero. 


\section{2) Statistical Differences of Narrow and Broad Variables}

The construction of a variance-bounds test requires the inducement of stationarity in the variables of interest. The literature contains many discussions of the importance of this requirement to narrow-dividend variance-bounds tests. The requirement remains critical when applying such tests to broad prices and dividends.

It is important to note that the stationarity properties of broad dividends will often differ from those of narrow dividends. Example 1 above gave one demonstration of such differences. More generally, consider the no-arbitrage case satisfying equation 15. In that case, the broad dividends and prices are

$$
\begin{aligned}
& P_{t+j} \equiv s_{t+j} p_{t+j} \\
& D_{t+j} \equiv s_{t+j-1} d_{t+j}+\left(s_{t+j-1}-s_{t+j}\right) p_{t+j}
\end{aligned}
$$

Choose any real number $\mathrm{s}^{*}$, and define

$$
\eta_{t+j} \equiv s_{t+j}-s^{*}
$$

Then the formula for broad dividends implies that

$$
\begin{aligned}
D_{t+j} & =s^{*} d_{t+j}+\eta_{t+j-1} d_{t+j}+\left(\eta_{t+j-1}-\eta_{t+j}\right) p_{t+j} \\
& =s^{*} d_{t+j}+\left[\eta_{t+j-1}\left(\frac{d_{t+j}}{p_{t+j}}\right)+\left(\eta_{t+j-1}-\eta_{t+j}\right)\right] p_{t+j} \\
& \equiv s^{*} d_{t+j}+e_{t+j} p_{t+j}
\end{aligned}
$$

Thus the stationarity properties of the broad dividend sequence $\left\{D_{t+j}\right\}$ will depend on the properties of both the narrow dividend sequence $\left\{d_{t+j}\right\}$ and the sequence $\left\{e_{t+j} p_{t+j}\right\}$. Knowledge of the stationarity properties of narrow dividends alone is not sufficient to deduce the properties of broad dividends. 
Further, consider the case in which the sequence of shares is monotonically nonincreasing and nonnegative. Any such sequence must converge to some limit. Taking $s^{*}$ to be that limit, and assuming that dividend/price ratios are well-behaved (e.g. if their support is a bounded subset of nonnegative real numbers), the resulting sequences $\left\{\eta_{t+j}\right\},\left\{\eta_{t+j-1}-\eta_{t+j}\right\}$, and $\left\{e_{t+j}\right\}$ must all be nonnegative and convergent to zero. Therefore the sequence $\left\{D_{t+j}-s^{*} d_{t+j}\right\}$ will be nonnegative, and will converge to 0 unless the sequence $\left\{p_{t+j}\right\}$ of share prices diverges at least as fast as the sequence $\left\{\varepsilon_{t+j}\right\}$ converges. If the limit of the share sequence is $s^{*}=0$, equation 18 implies that the asymptotic properties of the broad dividends will depend totally on the properties of $\left\{e_{t+j} p_{t+j}\right\}$, with no direct influence from the sequence $\left\{d_{t+j}\right\}$ of narrow dividends.

\section{3) The Economic Meaning}

Under the broad construct, the "price" variable $P_{t}$ is not simply the price of a security; it is instead the value of a portfolio. This distinction is critical to the interpretation of broad-dividend volatility tests.

Suppose that a broad-dividend variance-bounds test finds that the sequence $\left\{P_{t}\right\}$ is not excessively volatile relative to the volatility of the sequence $\left\{D_{t}\right\}$. The appropriate conclusion is that "Portfolio values were not seen to be excessively volatile given the observed volatility of the combined dividend payments and portfolio reductions." More pointedly, we cannot directly conclude anything about the relationship between share prices and expected per-share dividends, because these variables were not directly part of the test; it is possible in the broad approach that the effect of volatile share liquidations is masking volatility of share prices that is unrelated to changes in expected dividends.

For example, consider again the case in which liquidations always occur at cumdividend market prices, and assume that the sequence of shares is monotonically nonincreasing and convergent to $s^{*}>0$. Equation 18 demonstrates that the sequence of broad dividends has two components: The first component is the narrow dividends that would be paid on a portfolio of $s^{*}$ shares that are bought and held forever; the second component is the combined effect of fluctuations in share holdings and fluctuations in prices (which may or may not be related to fluctuations in expected dividends or other fundamentals). The second component is the only source of volatility in shareholder 
cash flows that would be found in a broad-dividend volatility test that would not likewise be observed in a narrow-dividend volatility test. However, this second source of volatility includes a component that is a result (not a cause) of share-price volatility; if a broad-dividend variance-bounds test fails to detect excess volatility (of portfolio values) because of this price-volatility component in broad dividends, it clearly would be inappropriate to conclude that share prices themselves are "justified" by the observed shareholder cash flows.

This suggests that broad-dividend volatility tests may lack power to detect share mispricing. I next demonstrate through simulations that such a loss of power likely influenced the results of the most prominent empirical test using broad dividends, the study by Ackert and Smith (1993).

\section{Demonstration of a Loss of Power in a Broad-Dividend Test}

Ackert and Smith (1993) uses a volatility test designed by West (1988). Unlike West, who applied the test only to narrow dividends, Ackert and Smith performed the West test under both the narrow and broad constructs, using data from the Toronto Stock Exchange from January 1951 through February 1991. Their method of constructing the broad dividend series resulted in the "special case" properties discussed above: In their data, narrow and broad returns are equal, and share holdings are nonnegative and monotonically nonincreasing. ${ }^{8}$

Consistent with the multitude of rejections in preceding (narrow-dividend) volatility studies, Ackert and Smith's results for the narrow construct solidly rejected NPVH-NB. Ackert and Smith's results for the broad-dividend volatility test also rejected BPVH-NB when broad dividends were assumed to be stationary in levels.

More interestingly, Ackert and Smith found that the broad-dividend variancebound test did not reject BPVH-NB when broad dividends were assumed stationary in

8. As shown by equation 11, the narrow and broad return series will be the same if and only if liquidation proceeds match cum-dividend prices. Share holdings in the data set are inferred from the ratios of broad prices to narrow prices: $s_{t} \equiv P_{t} / p_{t}$ 
first differences. Ackert and Smith conclude that this first-differenced acceptance was more reliable than the rejections obtained with undifferenced broad dividends because of previous empirical findings that narrow dividends are not stationary without differencing. ${ }^{9}$ They interpret this result as evidence that BPVH-NB holds, and that the rejections obtained in previous (narrow-dividend) volatility studies resulted from misspecifications of the relevant cash flows in those earlier tests.

However, the above analysis suggests a different interpretation. As shown earlier, if BPVH-NB holds then (under the assumptions made by Ackert and Smith) NPVH must also hold. Thus, Ackert and Smith's acceptance of BPVH-NB and rejection of NPVH-NB has only two possible interpretations (excluding sampling error): Either

1) Both BPVH-NB and NPVH hold, and Ackert and Smith's test of NPVH-NB rejected because of a rational or empirical bubble appearing in the narrow construct; or

2) Neither BPVH-NB nor NPVH-NB hold, and their broad-dividend test failed to reject because it lacked power to detect share mispricing.

The first of these two possible explanations appears doubtful. As shown above, satisfaction of BPVH-NB and NPVH would imply that the Euler condition is satisfied under Ackert and Smith's assumption of a constant discount rate. This would contradict the results of Hansen and Jagannathan (1991) and others who have demonstrated robustly that a constant-discount-rate assumption appears inconsistent with the Euler condition when teamed with historical returns. Satisfaction of the Euler condition evidently requires a time-varying discount rate and/or a revision of the historical return

9. This logic overlooks the result shown earlier, that stationarity properties of broad dividends can differ from those of narrow dividends because of the effects of changes in share holdings and prices. In fact, my estimation of an AR(12) process for Ackert and Smith's broad-dividend series had all roots within the unit circle (consistent with level-stationarity of broad dividends), despite the apparent nonstationarity of narrow-dividend levels. However, the broad-dividend data showed other signs of nonstationarity that may have affected Ackert and Smith's results, such as an apparent increase in variance for the disturbances in the broad-dividend process from the first half of the sample to the second half. These concerns over the stationarity assumptions by Ackert and Smith are peripheral to the main point of this paper, and so are not discussed further. 
series - however, neither of these appear in Ackert and Smith's work. ${ }^{10}$

By contrast, the second possible explanation - a lack of power in the broaddividend test - is supported by a simulation exercise. In each simulation, I assumed that first-differenced narrow dividends follow the AR(12) process identified from Ackert and Smith's monthly narrow-dividend data. Using these parameters, I simulated streams $\left\{d_{t}\right\}$ of narrow dividends, each stream having 494 periods (matching the sample length of Ackert and Smith). For each stream and each period $t$, I used the simulated narrow dividends from periods $t$ through $t-12$ (and the constant discount factor estimated from Ackert and Smith's data) to calculate the expected present value of future dividends using the formulas presented by Hansen and Sargent (1981); these are the correct narrow prices $\left\{p_{t}^{*}\right\}$ that would be observed in rational markets, given the assumed processes for dividends and discount rates. In contrast to these correct prices, I assumed that the actual market prices contained errors: Specifically, I assumed that actual market prices were given by $p_{t}=\left(1+\epsilon_{t}\right) p_{t}^{*}$, where $\left\{\epsilon_{\mathrm{t}}\right\}$ is a sequence of $i$ id shocks, drawn from zero-mean uniform distributions. ${ }^{11}$ The upper and lower limits of the distributions were determined to obtain mean absolute percent-pricing-errors (MAPPE) ranging from 0 to 20 percent:

10. Superficially, the first explanation also appears to contradict results of Santos and Woodford (1997), who show that the existence of rational bubbles requires satisfaction of some quite restrictive conditions that apparently contradict recent empirical findings. However, as previously discussed, it is possible that an empirical bubble could appear in observed data even when there is no true rational bubble. Thus, the Santos-Woodford result by itself does not completely address the question at hand.

11. With this process, actual prices will be less than the theoretically correct prices about half the time when MAPPE $>0$, and hence these differences cannot be rational bubbles. Also note that

$$
E_{t}\left(r_{t+1} \mid p_{t}>p_{t}^{*}\right)<E_{t}\left(r_{t+1} \mid p_{t}=p_{t}^{*}\right)<E_{t}\left(r_{t+1} \mid p_{t}<p_{t}^{*}\right)
$$

in violation of the constant-discount-rate assumption made in the West test. Thus, we could interpret a West test rejection as a failure of the constant-discount-rate assumption rather than a case of mispricing. See Cochrane (1991) and Schwert (1991). 


$$
\begin{aligned}
\epsilon_{t} \sim \text { uniform }[-2 \cdot \mathrm{MAPPE}, 2 \cdot \mathrm{MAPPE}] \\
M A P P E \equiv E\left\{\frac{\left|p_{t}-p_{t}^{*}\right|}{p_{t}^{*}}\right\} \equiv \text { mean absolute percent-pricing-error } \\
0 \leq M A P P E \leq .20
\end{aligned}
$$

I then used the simulated narrow dividends $\left\{d_{t}\right\}$, the narrow share prices $\left\{p_{t}\right\}$, and the sequence $\left\{s_{t} \equiv P_{t} / p_{t}\right\}$ of shares from Ackert and Smith's data to construct corresponding sequences of broad dividends and prices, using the formulas given in equations 17.

For each value of MAPPE, I used these procedures to construct 500 simulated sets of prices and dividends under both the narrow and broad approaches. I then applied the West test to each data set (narrow and broad), assuming stationarity in first-differences of each dividend series. I defined a rejection of the applicable NPVH-NB or BPVH-NB as a West statistic that is at least two estimated asymptotic standard errors less than zero.

Table 1 summarizes the simulation results.

As shown in the table, the narrow-dividend West test correctly rejected NPVH-NB for most simulations featuring MAPPEs of 2 percent or more. With MAPPEs of 4 percent or more, the narrow test successfully rejected in more than 94 percent of the simulations. ${ }^{12}$

By contrast, the broad-dividend test failed to reject BPVH-NB for any simulations in which the MAPPE was 4 percent or less. Even with pricing errors averaging 10 percent, the broad test failed to reject BPVH-NB in nearly half of the simulations. The broad test did not achieve a 90 percent rejection rate even with MAPPEs as high as 20 percent.

These simulation results suggest that if narrow dividends, share liquidations, and discount rates in fact matched the parameters implied in Ackert and Smith's data, the

12. Note that with no pricing error (i.e., with MAPPE $=0$ ), the narrow-dividend test incorrectly rejected NPVH-NB in 11 percent of the simulations, higher than the 2-3 percent rejection rate that would be expected from (simulated) sampling error. This is consistent with the results of West (1988), who similarly detected a slight bias of the (narrow-dividend) test toward rejection. 
West test applied to first-differenced broad dividends would likely fail to detect significant mispricing (and associated excess volatility) in share prices. Thus, the lack of power of the broad-dividend test likely explains why their results contradicted earlier volatility tests and other direct tests of the Euler condition.

\section{Conclusion}

The question at hand is whether either the broad-dividend or narrow-dividend approach to variance-bounds volatility tests is superior to the other. The above analysis demonstrates that under common assumptions the narrow and broad approaches are nearly equivalent in theory, but can generate different empirical results.

This observation reconciles the proponents and doubters of the broad approach. Doubters of the broad approach focus on the theoretical near-equivalence of the narrow and broad constructs: Because the narrow and broad present value hypotheses are equivalent up to possible differences related to bubbles, broad-dividend tests with sufficient power would be expected to reject the present value hypothesis unless previous rejections of (narrow-dividend) volatility tests were somehow attributable to bubbles. Proponents of the broad approach generally focus on the possible empirical advantages of the broad dividend approach when dividends are smoothed or when companies pay no dividends; as shown here, such dividend effects can generate "empirical bubbles" that might raise the probability of Type-1 error (i.e., incorrect rejection of the no-bubble present value hypothesis) in a narrow-dividend volatility test, but not in the broaddividend test.

However, proponents of the broad-dividend approach have not considered the possible loss of power that can increase the probability of Type 2 error (i.e., incorrect acceptance of the no-bubble present value hypothesis) in broad-dividend volatility tests. As demonstrated here, the broad-dividend approach can fail to detect substantial share-

pricing error and excess share-price volatility. It appears likely that this deterioration of power accounts for the differing results between broad and narrow volatility tests reported in the literature to date. 


\section{Table 1: A Simulated Comparison of the Power of Narrow- and Broad- Dividend Applications of the West Test ${ }^{1}$}

\begin{tabular}{|c|c|c|c|c|c|c|}
\hline \multirow[b]{2}{*}{$\mathrm{MAPPE}^{2}$} & \multicolumn{2}{|c|}{$\begin{array}{l}\text { Simulated } \\
\text { Monthly Returns }^{3}\end{array}$} & \multicolumn{2}{|c|}{ Mean t-Statistic ${ }^{4}$} & \multicolumn{2}{|c|}{$\begin{array}{r}\text { Rejection Rate } \\
(\mathrm{t}-\text { Stat }<-2)^{5}\end{array}$} \\
\hline & $\begin{array}{l}\text { Sample } \\
\text { Mean }\end{array}$ & $\begin{array}{l}\text { Mean } \\
\text { Sample } \\
\text { St. Dev. }\end{array}$ & $\begin{array}{c}\text { Narrow } \\
\text { Test }\end{array}$ & $\begin{array}{c}\text { Broad } \\
\text { Test }\end{array}$ & $\begin{array}{c}\text { Narrow } \\
\text { Test }\end{array}$ & $\begin{array}{c}\text { Broad } \\
\text { Test }\end{array}$ \\
\hline $0 \%$ & $0.5 \%$ & $2.6 \%$ & -0.3 & 1.5 & $11.0 \%$ & $0.0 \%$ \\
\hline $1 \%$ & $0.5 \%$ & $3.0 \%$ & -1.7 & 1.5 & $33.4 \%$ & $0.0 \%$ \\
\hline $2 \%$ & $0.6 \%$ & $4.2 \%$ & -4.4 & 1.3 & $74.0 \%$ & $0.0 \%$ \\
\hline $4 \%$ & $0.7 \%$ & $7.1 \%$ & -8.8 & 0.8 & $94.8 \%$ & $0.0 \%$ \\
\hline $8 \%$ & $1.4 \%$ & $13.6 \%$ & -10.8 & -1.0 & $98.2 \%$ & $15.6 \%$ \\
\hline $10 \%$ & $1.9 \%$ & $17.0 \%$ & -10.6 & -2.2 & $97.8 \%$ & $46.4 \%$ \\
\hline $12 \%$ & $2.5 \%$ & $20.6 \%$ & -10.1 & -3.5 & $97.0 \%$ & $61.8 \%$ \\
\hline $16 \%$ & $4.2 \%$ & $28.2 \%$ & -8.9 & -5.9 & $96.2 \%$ & $76.8 \%$ \\
\hline $20 \%$ & $6.5 \%$ & $36.6 \%$ & -7.9 & -7.0 & $96.4 \%$ & $84.6 \%$ \\
\hline
\end{tabular}

1. Results of 500 simulations for each shown value of MAPPE. Each simulation included a stream of 494 monthly dividends and market prices, generated using parameters obtained from data of Ackert and Smith (1993), plus the indicated average percent pricing errors.

2. Mean absolute percent pricing error - The average absolute percent difference between the market price and the theoretically correct price.

3. For each of the 500 simulations (for each given value of MAPPE), I calculated the mean of the 494 monthly returns implied by the simulated dividends and market prices. The "Sample Mean" column shows the mean of the 500 sample means at each MAPPE, while the "Mean Sample St. Dev." column shows the standard deviation of the 500 sample means.

4. For each simulation, the $\mathrm{t}$-statistic is the West statistic divided by its estimated asymptotic standard error. The values shown are the means of the $t$-statistics for the 500 simulations at each MAPPE, both for the narrow-dividend approach and the broad-dividend approach.

5. For each value of MAPPE, for both the narrow and broad approaches, the percentage of the 500 simulations that included a t-statistic less than -2 , indicating a statistically significant rejection of the "no-excess-price-volatility" null hypothesis WS $\geq 0$. 


\section{Appendix 1:}

\section{A Brief Note on Variance-Bounds Volatility Tests}

Variance-bounds tests were developed to test implications of the NPVH-NB (or, in some cases, NPVH). This appendix will not try to summarize all of the test methods that have been discussed in the literature; readers interested in surveys of the variance bound literature might start with Cochrane (1991) or Gilles and LeRoy (1991). It suffices here to note that these tests generally proceed as follows:

1) Assume some process for the discount rates in the NPVH.

2) Impose some transformation of prices and dividends to obtain observable, stationary variables.

3) Show that NPVH-NB (or NPVH) implies that the unconditional variance of the price-related variable (after transformation in step 2) is bounded by some function of the discount rates and the unconditional variance of the (transformed) dividend-related variable.

4) Estimate the discount rates and unconditional moments of the price- and dividend-related variables from some sample of historical prices and dividends.

5) Using the estimated values, test whether the variance bound from step 3 is satisfied.

Early variance bounds tests assumed that discount rates were constant (implying constant expected returns), and tended to suggest that stock price volatility exceeded the variance bounds, thereby implying that prices were excessively volatile relative to the model. Criticisms of the early variance bounds tests commonly focused on issues related to the potentially biasing effects of transformations and manipulations used to obtain testable variance bounds, especially assumptions about stationarity.

In response to these criticisms, West (1988) developed a variance bounds test (the "West test") that is somewhat flexible with regard to stationarity assumptions. The West test assumes that the representative investor's information set is the span of a finite set of 
variables (including the dividend and price history) that follow a covariance-stationary ARMA process after finite linear differencing. Like earlier tests, the West test assumes a constant discount rate $0<\gamma<1$. Defining $I_{t}$ as the full information set available to investors at time $t, H_{t}$ as only the dividend history, and

$$
\begin{aligned}
& p_{t}^{I} \equiv E\left(\sum_{j=0}^{\infty} \gamma^{j} d_{t+j} \mid I_{t}\right)=p_{t}+d_{t} \\
& p_{t}^{H} \equiv E\left(\sum_{i=0}^{\infty} \gamma^{j} d_{t+j} \mid H_{t}\right)
\end{aligned}
$$

West showed that the variance of the innovations in actual one-period payoffs should be less than the innovations in one-period payoffs estimated using the dividend history alone. Letting WS here denote the "West statistic", this result is stated as

$$
W S \equiv \operatorname{Var}\left[p_{t}^{H}-E\left(p_{t}^{H} \mid H_{t-1}\right)\right]-\operatorname{Var}\left[p_{t}^{I}-E\left(p_{t}^{I} \mid I_{t-1}\right)\right] \geq 0
$$

West also provides the formula for a consistent estimator of the variance of WS.

Using annual data for Standard and Poor (1873-1980) and Dow-Jones (1931-1978) indexes, West showed that the estimated values for WS were significantly negative, violating the variance bound and indicating excess price volatility relative to the model.

Because the form of the BPVH is identical in form to the NPVH, it may seem a simple mechanical exercise to apply these same variance bounds tests to the broadly defined measures of dividends and prices. However, as discussed in the paper, the broad and narrow variables have important differences that can affect the construction and interpretation of test results. 


\section{References}

Ackert, Lucy F. and Brian F. Smith (1993), “Stock Price Volatility, Ordinary Dividends, and Other Cash Flows to Shareholders", Journal of Finance, 48(4), pp. 1147-1160.

Campbell, John Y., Andrew W. Lo, and A. Craig MacKinlay (1997), The Econometrics of Financial Markets, Princeton University Press.

Cochrane, John H. (1991), "Volatility Tests and Efficient Markets: A Review Essay”, Journal of Monetary Economics, 27, pp. 463-485.

Diba, Behzad T. and Herschel I. Grossman (1988), "The Theory of Rational Bubbles in Stock Prices", Economic Journal, 98, pp. 746-754.

Flood, Robert P. and Robert J. Hodrick (1990), “On Testing for Speculative Bubbles", Journal of Economic Perspectives, 4(2), pp. 85-101.

Gilles, Christian and Stephen F. LeRoy (1991), “Econometric Aspects of the Variance Bounds Tests: A Survey", Review of Financial Studies, 4(4), pp. 753-791.

Hansen, Lars Peter and Ravi Jagannathan (1991), “Implications of Security Market Data for Models of Dynamic Economies", Journal of Political Economy, 99, pp. 225-262.

Hansen, Lars Peter and Thomas J. Sargent (1981), “Formulating and Estimating Dynamic Linear Rational Expectations Models", in Rational Expectations and Econometric Practice (eds. Robert E. Lucas, Jr. and Thomas J. Sargent), Univ. of Minnesota Press, pp. 91-126.

LeRoy, Stephen F. and Richard D. Porter (1981), “The Present-Value Relation: Tests Based on Implied Variance Bounds", Econometrica, 49(3), pp. 555-574.

LeRoy, Stephen F. and Garrett H. TeSelle (1995), “Stock Price Volatility: A Comment:", unpublished manuscript.

Marsh, Terry A. and Robert C. Merton (1986), "Dividend Variability and Variance Bounds Tests for the Rationality of Stock Market Prices", American Economic Review, 76, pp. 483-498.

Penman, Stephen H. and Theodore Sougiannis (1997), “A Comparison of Dividend, Cash Flow, and Earnings Approaches to Equity Valuation", unpublished working paper.

Pontiff, Jeffrey (1997), “Excess Volatility and Closed-End Funds”, American Economic Review, 87(1), pp. 155169.

Santos, Manuel S. and Michael Woodford (1997), "Rational Asset Pricing Bubbles", Econometrica, 65(1), pp. 1957.

Schwert, G. William (1991), “Review of Market Volatility by Robert J. Shiller", Journal of Portfolio Management, pp. 74-78.

Shiller, Robert J. (1981), “Do Stock Prices Move by Too Much to be Justified by Subsequent Changes in Dividends?", American Economic Review, 71, pp. 421-436.

Shoven, John B. (1987), “Tax Consequences of Share Repurchases and Other Non-Dividend Cash Payments to Equity Owners", in Tax Policy and the Economy, Vol 1. (ed. Lawrence H. Summers), NBER and MIT Press.

West, Kenneth D. (1988), “Dividend Innovations and Stock Price Volatility”, Econometrica, 56(1), pp. 37-61. 